By: Dale H. Schunk

Schunk, D. H. (1991). Self-efficacy and academic motivation. Educational Psychologist, 26, 207-231.

Made available courtesy of Taylor and Francis: http://www.tandf.co.uk/journals/

$* * *$ Reprinted with permission. No further reproduction is authorized without written permission from Taylor and Francis. This version of the document is not the version of record. Figures and/or pictures may be missing from this format of the document. $* * *$

\begin{abstract}
:
Academic motivation is discussed in terms of self-efficacy, an individual's judgments of his or her capabilities to perform given actions. After presenting an overview of self-efficacy theory, I contrast self-efficacy with related constructs (perceived control, outcome expectations, perceived value of outcomes, attributions, and selfconcept) and discuss some efficacy research relevant to academic motivation. Studies of the effects of person variables (goal setting and information processing) and situation variables (models, attributional feedback, and rewards) on self-efficacy and motivation are reviewed. In conjunction with this discussion, I mention substantive issues that need to be addressed in the self-efficacy research and summarize evidence on the utility of self-efficacy for predicting motivational outcomes. Areas for future research are suggested.
\end{abstract}

\title{
Article:
}

The concept of personal expectancy has a rich history in psychological theory on human motivation (Atkinson, 1957; Rotter, 1966; Weiner, 1979). Research conducted within various theoretical traditions supports the idea that expectancy can influence behavioral instigation, direction, effort, and persistence (Bandura, 1986; Locke \& Latham, 1990; Weiner, 1985).

In this article, I discuss academic motivation in terms of one type of personal expectancy: self-efficacy, defined as "People's judgments of their capabilities to organize and execute courses of action required to attain designated types of performances" (Bandura, 1986, p. 391). Since Bandura's (1977) seminal article on selfefficacy, much research has clarified and extended the role of self-efficacy as a mechanism underlying behavioral change, maintenance, and generalization. For example, there is evidence that self-efficacy predicts such diverse outcomes as academic achievements, social skills, smoking cessation, pain tolerance, athletic performances, career choices, assertiveness, coping with feared events, recovery from heart attack, and sales performance (Bandura, 1986).

After presenting an overview of self-efficacy theory and comparison of self-efficacy with related constructs, I discuss some self-efficacy research relevant to academic motivation, pointing out substantive issues that need to be addressed. I conclude with recommendations for future research.

\section{SELF-EFFICACY THEORY}

Antecedents and Consequences

Bandura (1977) hypothesized that self-efficacy affects an individual's choice of activities, effort, and persistence. People who have a low sense of efficacy for accomplishing a task may avoid it; those who believe they are capable should participate readily. Individuals who feel efficacious are hypothesized to work harder and persist longer when they encounter difficulties than those who doubt their capabilities.

Self-efficacy theory postulates that people acquire information to appraise efficacy from their performance accomplishments, vicarious (observational) experiences, forms of persuasion, and physiological indexes. An individual's own performances offer the most reliable guides for assessing efficacy. Successes raise efficacy and 
failure lowers it, but once a strong sense of efficacy is developed, a failure may not have much impact (Bandura, 1986).

An individual also acquires capability information from knowledge of others. Similar others offer the best basis for comparison (Schunk, 1989b). Observing similar peers perform a task conveys to observers that they too are capable of accomplishing it. Information acquired vicariously typically has a weaker effect on self-efficacy than performance-based information; a vicarious increase in efficacy can be negated by subsequent failures.

Students often receive persuasory information that they possess the capabilities to perform a task (e.g., "You can do this"). Positive persuasory feedback enhances self-efficacy, but this increase will be temporary if subsequent efforts turn out poorly. Students also derive efficacy information from physiological indexes (e.g., heart rate and sweating). Bodily symptoms signaling anxiety might be interpreted to indicate a lack of skills.

Information acquired from these sources does not automatically influence efficacy; rather, it is cognitively appraised (Bandura, 1986). Efficacy appraisal is an inferential process in which persons weigh and combine the contributions of such personal and situational factors as their perceived ability, the difficulty of the task, amount of effort expended, amount of external assistance received, number and pattern of successes and failures, their perceived similarity to models, and persuader credibility (Schunk, 1989b).

Self-efficacy is not the only influence on behavior; it is not necessarily the most important. Behavior is a function of many variables. In achievement settings some other important variables are skills, outcome expectations, and the perceived value of outcomes (Schunk, 1989b). High self-efficacy will not produce competent performances when requisite skills are lacking. Outcome expectations, or beliefs concerning the probable outcomes of actions, are important because individuals are not motivated to act in ways they believe will result in negative outcomes. Perceived value of outcomes refers to how much people desire certain outcomes relative to others. Given adequate skills, positive outcome expectations, and personally valued outcomes, self-efficacy is hypothesized to influence the choice and direction of much human behavior (Bandura, 1989b).

Schunk (1989b) discussed how self-efficacy might operate during academic learning. At the start of an activity, students differ in their beliefs about their capabilities to acquire knowledge, perform skills, master the material, and so forth. Initial self-efficacy varies as a function of aptitude (e.g., abilities and attitudes) and prior experience. Such personal factors as goal setting and information processing, along with situational factors (e.g., rewards and teacher feedback), affect students while they are working. From these factors students derive cues signaling how well they are learning, which they use to assess efficacy for further learning. Motivation is enhanced when students perceive they are making progress in learning. In turn, as students work on tasks and become more skillful, they maintain a sense of self-efficacy for performing well.

\section{Related Constructs}

The notion that personal expectancies can influence behavior is not new. Tolman (1932), for example, believed that much learning involved the forming of expectancies that certain behaviors will produce given outcomes. There are several constructs that resemble self-efficacy: perceived control, outcome expectations, perceived value of outcomes, attributions, and self-concept. Comparing self-efficacy with these constructs will illuminate the unique features of each.

Perceived control. Perceived control is a widely used umbrella term that has been defined in various ways. Rotter's (1966) locus of control, for example, emphasizes perceived control over outcomes. People differ in whether they believe that outcomes (a) occur independently of how they act and are due to such factors as luck, chance, or fate (external control) or (b) are highly contingent on their actions (internal control). A related construct is learned helplessness, a psychological state involving a disturbance in motivation, cognition, and emotions as a result of previously experienced uncontrollability (Seligman, 1975). Helplessness results from a perceived independence between responses and outcomes. 
Skinner and her colleagues (Skinner, Chapman, \& Baltes, 1988; Skinner, Wellborn, \& Connell, 1990) recently proposed a model of perceived control that comprises three sets of beliefs: means-ends or strategy beliefs referring to the extent that potential causes produce given outcomes, agency or capacity beliefs about whether the individual has or can acquire the potential causes, and control beliefs concerning whether the individual can produce the desired outcome without reference to any particular means. With respect to effort, for example, an individual might hold a means-ends belief that studying hard will produce a good grade, a capacity belief that he or she can study hard, and a control belief that he or she can get a good grade. Although there is some overlap between categories, self-efficacy seems analogous to capacity beliefs (e.g., "I believe I can study hard").

Bandura (1986, 1989a) defined a personal control system as comprising self-efficacy and outcome expectations. Self-efficacy theory originally referred to an individual's perceived capabilities to control his or her performance in emotionally taxing or otherwise difficult situations (Bandura, 1977). The theory has since been expanded to include perceived capabilities to control such self-referent activities as cognitive processes, emotions, and selfregulated behaviors.

Although perceived control over outcomes is important, it does not guarantee that students will be motivated or will learn. Students might believe that their teacher will be pleased if they make a high grade on the next exam (positive outcome expectation), but they may seriously doubt their capabilities to learn the material on the exam (low self-efficacy). This is not to imply that self-efficacy and outcome beliefs are unrelated. Students who feel capable of learning and performing well in school expect, and usually receive, outcomes commensurate with their high performances (e.g., good grades and honor roll). Self-efficacy and outcome expectations are separable in situations where outcomes are poorly linked with performance quality (e.g., teacher gives all students high grades, regardless of performance).

Expectations and values. Expectancy-value theories stress the notion that behavior is a joint function of (a) people's expectations of obtaining a particular outcome as a function of performing a behavior and (b) the extent that they value those outcomes (Atkinson, 1957; Eccles, 1983; Vroom, 1964). These theories assume that people make judgments of the likelihood of attaining various goals in given situations. They are not motivated to attempt the impossible, so they do not pursue goals perceived as unattainable. Even a positive outcome expectation does not produce action if the goal is not valued. An attractive goal, along with the belief it is attainable, motivates people to act.

Outcome expectations and values influence, but do not guarantee, motivation and learning. Students who value teacher praise and believe that learning to spell the week's words will produce praise will not be motivated to learn the words if they doubt their capabilities to do so. Self-efficacy theory differs from expectancy-value formulations in its emphasis on students' beliefs concerning their capabilities to learn and effectively employ the skills and knowledge necessary to attain the valued outcomes.

Attributions. Attributions are perceived causes of outcomes. Attribution theories assume that people seek to explain the causes of significant events (Heider, 1958; Kelley \& Michela, 1980; Weiner, 1985). In achievement situations, students often attribute their successes and failures to such factors as ability, effort, task difficulty, and luck (Weiner, 1979). In turn, attributions influence expectancies of future successes. Assuming that the learning conditions are expected to remain much the same, students who attribute prior successes largely to stable factors (e.g., high ability or easy task) are apt to hold higher expectancies for success than those who emphasize less stable factors (e.g., high effort or good luck).

In self-efficacy theory, attributions constitute one type of cue that students use to appraise efficacy. Attributional factors such as the amount of effort expended and judgments of task difficulty influence performance indirectly through self-efficacy (Bandura, 1986). For example, students who succeed through high effort are likely to judge themselves less capable than those who succeed with ease. Success on a task judged as easy will not raise self-efficacy as much as success on a difficult task. Efficacy appraisals depend on 
attributional factors as well as other influences, such as situational circumstances under which performances occur, number and pattern of successes, and persuader credibility.

Self-concept. Self-concept is an individual's collective self-perceptions that are (a) formed through experiences with, and interpretations of, the environment and (b) heavily influenced by reinforcements and evaluations by significant other persons (Shavelson \& Bolus, 1982). Self-concept is multidimensional and comprises selfesteem, self-confidence, stability, and self-crystallization (Rosenberg \& Kaplan, 1982). Self-esteem is an individual's perceived sense of self-worth, that is, whether an individual accepts or respects him or herself. Selfconfidence is an individual's belief that he or she has the ability to produce results, accomplish goals, or perform tasks competently. Stability refers to the ease or difficulty of changing the self-concept, and it depends on how crystallized or structured an individual's self-beliefs are. Beliefs become crystallized with repeated similar experiences.

Although most investigators postulate a general self-concept, recent evidence indicates that the self-concept is hierarchically organized (Marsh \& Shavelson, 1985), with a general self-concept at the top and subarea selfconcepts at the base. Self-perceptions of specific behaviors presumably influence subarea self-concepts (e.g., English or mathematics), which in turn combine to form the academic self-concept. The general self-concept is formed by self-perceptions in the academic area combined with those in nonacademic (social, emotional, and physical) domains.

Self-concept is a global construct comprising self-efficacy and other aspects of the self. Of self-concept's various dimensions, self-confidence seems the most akin to self-efficacy. In the hierarchy, self-efficacy judgments would lie at low levels because they are generally construed to be domain specific. How much selfefficacy generalizes across domains remains to be shown (the generality issue is discussed later in this article).

Bandura (1986) contended that general measures of psychological functioning cannot predict with accuracy what people will do in specific situations. This is because, to arrive at a global judgment, people must integrate information from divergent and often conflicting sources. For example, self-concept includes individuals' perceptions of their self-confidence and their self-esteem, and there is not necessarily a relation between them. Students may judge themselves highly capable in intellectual endeavors and feel a great sense of self-worth, moderately competent in social situations but feel inadequate, and low in competence in athletic pursuits but not feel inadequate. Within the academic area, a high self-concept does not imply that students feel highly confident in all academic areas. Students might judge their competence high in science and mathematics, moderate in English and social studies, and low in French and Latin. Within mathematics, students might feel efficacious about algebra but not geometry. Self-efficacy theory holds that the best predictors of behavior in specific situations are individuals' self-perceptions within those situations (Bandura, 1989b; Schunk, 1989b).

\section{RESEARCH AND SUBSTANTIVE ISSUES}

The role that self-efficacy plays in academic motivation can be illustrated by summarizing some relevant research. Unless otherwise noted, the studies reviewed included measures of self-efficacy and motivation. This review is not comprehensive or exhaustive; I omitted methodological details to conserve space. Interested readers should consult other reviews (Bandura, 1986; Foersterling, 1985; Locke \& Latham, 1990; Schunk, 1987, 1989a) for comprehensive accounts of the topics covered in this section.

The studies are grouped according to whether they focused primarily on person or situation variables, although some studies (e.g., Schunk, 1983b) addressed both. The person variables selected for review are goal setting and information processing; the situation variables are models, attributional feedback, and rewards. At the end of this section, I discuss research on the predictive utility of self-efficacy.

\section{Goal Setting}

Goal setting is hypothesized to be an important cognitive process affecting motivation (Bandura, 1988; Locke \& Latham, 1990; Schunk, 1989a). This link can be illustrated with students who set a goal or are given a goal by 
teachers. They are likely to experience an initial sense of self-efficacy for attaining it. They also are apt to make a commitment to attempt it, which is necessary for goals to affect performance. As they work at the task, they engage in activities they believe will lead to goal attainment: attend to instruction, rehearse information to be remembered, expend effort, and persist. Self-efficacy is substantiated as learners observe goal progress, which conveys they are becoming skillful (Elliott \& Dweck, 1988). Providing students with feedback on goal progress also raises self-efficacy (Bandura \& Cervone, 1983).. Heightened self-efficacy sustains motivation and improves skill development.

The motivational benefits of goals depend on their properties: proximity, specificity, and difficulty. Proximal (close-at-hand) goals promote self-efficacy and motivation better than distant goals, because students can judge progress toward the former easier than toward the latter. For the same reason, goals that incorporate specific performance standards raise efficacy and motivation better than general goals (e.g., "Do your best"). Pursuing easier goals may enhance efficacy and motivation during the early stages of skill acquisition, but difficult goals are more effective as skills develop because they offer more information about capabilities.

The hypothesized benefits of goal setting have been obtained in several studies. Bandura and Schunk (1981) found that, during a subtraction instruction program, providing children with a proximal goal heightened motivation (rate of problem solving), self-efficacy, and skill acquisition, more than did providing them a distant or general ("Do your best") goal. The distant goal resulted in no benefits compared with the general goal. During a long-division instruction program, Schunk (1983b) showed that giving children specific performance goals plus comparative information about peers that indicated that the goal was attainable led to higher skill than did either treatment alone. Goals by themselves enhanced self-efficacy; comparative information promoted motivation.

Schunk (1983c) found that, compared with easier goals, difficult goals raised children's motivation during arithmetic instruction. Giving children persuasory information ("You can work 25 problems") increased selfefficacy; difficult goals plus persuasory information led to the highest skill. Locke, Frederick, Lee, and Bobko (1984) investigated goal difficulty during brainstorming by college students as they gave uses for objects. Students set or were assigned goals. Efficacy for moderate to difficult goals predicted students' performances. Efficacy and goal commitment related positively among subjects who set their goals. Among students who were taught a strategy to generate uses, the strategy training affected level of goal setting through self-efficacy.

Allowing students to set goals may enhance goal commitment. Schunk (1985) found that self-set goals also promote self-efficacy. Sixth-grade learning-disabled students received subtraction instruction. Children who set their own performance goals and those who had goals assigned demonstrated greater motivation than subjects who had no goals, but self-set goals led to the highest self-efficacy and skill.

One problem with much goal-setting research is that it studies effects over short periods. This type of research can study basic processes, but it does not fully capture the nature of academic motivation. Academic goals often are long term: earn a college degree, complete a science fair project, raise one's grade point average. We need research exploring goal setting over lengthy periods. Along these lines, Morgan (1985) found that proximal goals raised academic performance and intrinsic interest among college students over an academic year. Although efficacy was not assessed in this study, the results suggest that goal proximity may affect selfregulatory processes associated with studying over time. Investigating students' goal setting over longer periods can determine how they self-regulate their motivation and how efficacy changes as they progress toward longterm goals.

\section{Information Processing}

Research has investigated the notion that students' self-efficacy about their capabilities to cognitively process academic material can influence motivation and learning. Schunk (1989b) postulated that students who believe they will experience much difficulty comprehending material are apt to hold a low sense of efficacy for learning it, whereas those who feel they are capable of handling the information-processing demands should feel more 
efficacious. A higher sense of efficacy leads students to perform those activities that they believe will result in learning. As students work on tasks, they derive information about how well they are learning. The perception that they are comprehending material enhances efficacy and motivation. The perception that little progress is being made may not lower efficacy and motivation if students believe they can perform better by altering their task approach.

Salomon (1984) found that self-efficacy relates to mental effort. Children judged their efficacy for learning from television or from written text, watched a televised film or read the comparable text, judged the amount of mental effort necessary to learn, and were tested on the content. Students judged mental effort greater for text and demonstrated higher achievement scores from text. For text learning, self-efficacy correlated positively with mental effort and achievement; for television learning, it correlated negatively. Students who watched television felt more efficacious about learning but expended less effort and achieved at a lower level.

Among college students, Meier, McCarthy, and Schmeck (1984) demonstrated that efficacy for writing relates to cognitive processing dimensions. Students wrote essays at the beginning and end of a semester and judged efficacy for accomplishing course writing objectives. Efficacy accurately predicted writing performance. Information-processing indexes relating to efficacy were synthesis-analysis (searching for meaning by categorizing ideas and comparing and contrasting categories) and elaborative processing (personalizing and concretizing by relating ideas to personal experiences).

There is much research on student's learning strategies, systematic plans that assist encoding of information and task performance (Weinstein \& Mayer, 1986). Learning strategies improve achievement on the task at hand and generalize beyond the learning context (Borkowski, 1985). Strategies typically are viewed as aids to learning, but they also may influence self-efficacy and motivation (Corno \& Mandinach, 1983). The belief that a strategy has been learned that improves learning can instill a sense of control over achievement outcomes, which raises self-efficacy and leads the learner to apply the strategy diligently (Corno, 1989; Schunk, 1989b). To the extent that strategy use improves task performance, a student's efficacy is substantiated and he or she continues to apply the strategy.

Self-efficacy relates positively to motivation to employ learning strategies. Pintrich and De Groot (1990) had seventh graders judge efficacy and use of various strategies, including effort management and persistence. Efficacy was positively related to reported strategy use. Zimmerman and Martinez-Pons (1990) had students in Grades 5, 8, and 11 judge use of various learning strategies that included motivational components, as well as their efficacy for performing mathematical and verbal tasks. Efficacy related positively to reported strategy use across domains.

Instructional studies have substantiated the idea that teaching students to use strategies raises self-efficacy and achievement. Schunk and Gunn (1985) showed that modeled strategies enhance self-efficacy and motivation during mathematics instruction. Children observed a model emphasize the importance of strategy use or the importance of positive achievement beliefs (effort and efficacy), or both. Modeled importance of strategy use enhanced motivation and skills; emphasizing strategy use and positive beliefs led to the highest self-efficacy.

Schunk and Cox (1986) found that having learning-disabled students verbalize the steps in the strategy while applying it raises motivation, efficacy, and skill. Verbalization - a form of rehearsal - requires that students attend to important task features and assists coding and retention. Schunk and Cox found the greatest benefits when students verbalized throughout the instructional program. Students told to discontinue verbalizations midway through the study apparently failed to internalize the strategy and discontinued its use. Having students fade verbalizations to a covert (silent) level may help them self-regulate their performances.

The preceding research highlights important relations between cognitive processing and self-efficacy. Future studies should investigate in depth the relation between changes in information processing (including strategy use), self-efficacy, motivation, and learning as students work on tasks. Researchers in such domains as writing 
and mathematics often have students verbalize aloud as they work on tasks to determine differences between the cognitive processes of more and less- skilled students and how cognitive processes change as skills develop (Romberg \& Carpenter, 1986; Scardamalia \& Bereiter, 1986). Along with think-aloud sessions, efficacy research could include periodic assessments of efficacy over extended periods, to determine the relations between changes in the various measures.

\section{Models}

Students acquire much information about their capabilities from knowledge of how others perform. Classroom models - teacher and peer-are important sources of vicarious efficacy information. Observing others succeed can convey to observers that they too are capable and can motivate them to attempt the task. Conversely, observed failures may lower students' sense of efficacy and dissuade them from working on the task. Such vicarious effects may be negated by subsequent personal experiences. A vicarious increase in efficacy may be short lived if an observer subsequently attempts the task and performs poorly (Schunk, 1989a).

Research demonstrates the benefits of observing models on efficacy and motivation. In a study by Zimmerman and Ringle (1981), children observed a model who verbalized statements of confidence or pessimism while unsuccessfully attempting to solve a puzzle for a long or short time; then the children attempted the puzzle themselves. Observation of a model exhibiting high persistence and high confidence promoted children's motivation (persistence). Observing a low-persistence, high-confidence model raised self-efficacy; observing a high-persistence, high-pessimism model lowered children's efficacy. Relich, Debus, and Walker (1986) found that exposing low-achieving children to models explaining mathematical division increased these children's motivation (persistence); combining modeling with attributional feedback stressing ability and effort led to the greatest increase in self-efficacy.

Brown and Inouye (1978) investigated perceived similarity in competence. College students judged selfefficacy for solving anagrams and attempted to solve them. Subjects were told they performed better than or the same as a model, observed a model fail, judged efficacy, and attempted the anagrams again. Telling students they were more competent than the model led to higher efficacy and persistence than telling them they were equal in competence.

Schunk and Hanson (1985) compared observation of peer mastery and of peer coping models with observation of adult (teacher) models and no models. Peer mastery models solved subtraction with regrouping problems correctly and verbalized statements reflecting high self-efficacy and ability, low task difficulty, and positive attitudes. Peer coping models initially made errors and verbalized negative statements, but then verbalized coping statements (e.g., "I need to pay attention to what I'm doing") and eventually performed (and verbalized) as well as mastery models.

Observation of peer models increased efficacy and skill better than observation of the teacher model or no model; students who watched the teacher model outperformed students who watched no model. Children exposed to models displayed higher motivation (rate of problem solving) during instruction than did children who did not observe a model. Schunk and Hanson (1985) expected that their low-achieving subjects would identify more closely with the peer coping models, but no differences were obtained between mastery and coping models. Although subjects' prior subtraction successes were limited to problems without regrouping, they might have drawn on these and felt that if the models could learn, they could too.

In a follow-up study, Schunk, Hanson, and Cox (1987) used a task (fractions) on which children had experienced few successes. This study also tested the idea that observing multiple models is better than observing a single model because it increases the likelihood that students will view themselves similar to at least one model (Schunk, 1987). Observation of multiple models - coping and mastery - promoted outcomes as well as observation of a single coping model and better than observation of a single mastery model. Children who observed single models judged themselves more similar in competence to coping than mastery models. Benefits of observation of multiple models were not due to perceived similarity in competence. 
Research also has addressed self-modeling, cognitive and behavioral changes stemming from observing oneself on tape. Schunk and Hanson (1989) videotaped children solving problems and showed them their tapes.

Subsequent self-modeling benefits were obtained on measures of self-efficacy and motivation: These children outperformed students who had been videotaped but did not observe their tapes and those who had not been videotaped. These results suggest that self-model tapes highlight progress in skill acquisition, which enhances self-efficacy.

These results offer insights into the operation of modeling processes and their effects on self-efficacy and motivation. More information is needed on the role of perceived similarity to models. Results of the Schunk et al. (1987) study suggest that similarity may be important when students have few cues to assess efficacy. In school, children learn from all types of models, including teachers who are dissimilar in age, competence, and other characteristics. They also weigh and combine efficacy information from diverse sources; for example, they may observe peers succeed and receive positive feedback from teachers (e.g., "You can do this"), but experience difficulties when they attempt the task themselves. Research should explore the conditions under which similarity is important.

\section{Attributional Feedback}

Attributional feedback is hypothesized to have important effects on efficacy and motivation (Bandura, 1986; Weiner, 1979). Effort feedback for prior successes supports students' perceptions of their progress, sustains motivation, and increases efficacy for learning (Schunk, 1989b). The timing of feedback also is important. Early successes signal high learning ability; feedback for early successes can enhance learning efficacy. Effort feedback for early successes should be more credible when students have to work hard to succeed.

Research has supported these ideas. Schunk (1982) found that linking children's prior achievements with effort (e.g., "You've been working hard") leads to higher motivation, self-efficacy, and skill than emphasizing the potential benefits of effort ("You need to work hard"). Schunk (1983a) showed that ability feedback for successes ("You're good at this") enhances self-efficacy and skill better than effort feedback or ability-effort feedback. Although these three conditions raised children's motivation equally well, subjects who received ability-effort feedback judged effort expenditure greater than those who received feedback on ability only. Subjects who received ability-effort feedback may have discounted ability information in favor of effort.

In a study by Schunk and Cox (1986), learning-disabled students in middle school either received effort feedback during the first or second half of an instructional program or received no effort feedback. Students who received feedback in either half showed more motivation, self-efficacy, and skill than did subjects who received no feedback; feedback given in the first half increased effort attributions and motivation during the first half of the program. Given the students' learning disabilities, effort feedback for early or later successes seemed credible because they had to work hard to succeed. They may have interpreted the feedback as indicating they were becoming skillful and were capable of further learning.

We need to explore the role of attributional feedback over extended periods, specifically, how students interpret feedback at different stages of skill development. For example, effort feedback may be credible in the early stages of learning when students need to expend effort to succeed. As skills develop, they ought to succeed with less effort; thus, ability feedback may become more credible. Effort feedback over an extended period might actually lower self-efficacy, because as students become more skillful they might wonder why they still have to work hard to succeed. Periodic assessments of students' skills, efficacy, and interpretations of feedback could yield information about feedback sequences that optimally affect achievement outcomes.

\section{Rewards}

According to Bandura (1986), rewards are informative and motivating. As students work at tasks, they learn which actions lead to success and which to failure. Such information guides actions. Anticipation of desirable outcomes motivates students to persist. Rewards enhance efficacy when they are linked with a student's 
accomplishments and convey that the student has made progress in learning. Receipt of the reward also symbolizes progress. Rewards offered for task participation do not convey the same type of progress information.

Research supports these ideas. During mathematics instruction, children were told either that they would earn points for each problem solved and could exchange points for prizes (performance-contingent rewards) or that they would receive prizes for participating (task-contingent rewards; Schunk, 1983d). Performance-contingent rewards enhanced motivation, self-efficacy, and skill. Offering rewards for participation led to no benefits. Schunk (1984) found that performance-contingent rewards raised motivation as well as proximal goals among children during division instruction and that combining rewards with goals resulted in the highest efficacy and learning. Combining rewards with goals may have provided clear information to children about their learning progress.

Much has been written about the deleterious effect on intrinsic interest of offering students rewards for performing tasks they enjoy (Lepper, 1983). Less has been written about ways to help students develop interests. The development of interest likely depends in part on a sense of perceived competence for the activity (Lepper, 1983). Research needs to explore the idea that rewards may help to develop interest when they are given contingent on performance and thus signal progress in learning and raise efficacy. Lepper noted that this approach should be maximally effective with activities that have clear performance standards so that when students receive rewards they will understand what they denote. Given the prevalence of rewards in education, this research would have important implications for classroom practice.

\section{Predictive Utility}

Researchers have examined how well self-efficacy predicts motivational outcomes. Significant and positive correlations ( $\mathrm{rs}=.38$ to .42 ) have been obtained between self-efficacy for learning assessed before receiving instruction and subsequent rate of problem solving (Schunk \& Hanson, 1985; Schunk et al., 1987). In the Schunk (1982) study, multiple regression showed that rate of problem solving during instruction and posttest selfefficacy accounted for significant increments in posttest skill variability (change in $\mathrm{R}^{2}=.48$ for rate of problem solving and .20 for self-efficacy). Shell, Murphy, and Bruning (1989) did not include motivational outcomes but found that self-efficacy accounted for significant portions of the variability in both reading and writing achievement.

Schunk (1981) employed path analysis to reproduce a correlation matrix comprising instructional treatment, self-efficacy, persistence in solving problems, and division skill. The most parsimonious model showed a direct effect of treatment on skill, an indirect effect of treatment through persistence and efficacy on skill, an indirect effect of treatment through efficacy on persistence, and a direct effect of efficacy on skill and persistence.

Collins (1982) demonstrated that self-efficacy predicts motivation and achievement across levels of student ability. Children identified as high, average, or low in mathematical ability, were classified as high or low in efficacy for solving word problems. Students were given problems to solve (some were insolvable) and could rework any they missed. Low- and average-ability students with high efficacy worked on insolvable problems longer than did low-efficacy students. Regardless of ability, students with higher efficacy reworked more problems than did students with lower efficacy.

\section{FUTURE DIRECTIONS}

In his 1977 article, Bandura stated, "Further research on the processes postulated in the present theoretical formulation should increase our understanding of the relationship between cognitive and behavioral change" ( $p$. 212). As shown by the preceding review, research supports his contention that self-efficacy theory is useful for explaining academic motivation.

In the following sections I offer an agenda for future research. These suggestions derive from theory and research findings and will help to clarify our understanding of the role that self-efficacy plays in academic motivation. 


\section{Indexes of Academic Motivation}

Bandura (1986) cited much evidence supporting the notion that self-efficacy influences choice of activities, effort, and persistence. These effects are seen most clearly in contexts where behavior reflects performance of previously learned skills (e.g., coping with feared situations).

In school, the influence of self-efficacy on these motivational outcomes is more complex because learning is taking place. For example, choice of activities is not a good index of academic motivation because students typically do not choose whether to participate in learning activities (Brophy, 1983). Although choice is meaningful under a limited set of conditions (e.g., activities during free time), it represents a narrow motivational focus because choices available to students usually are limited.

There also are problems with persistence. Much clinical research shows that in feared situations people judge efficacy low and do not persist at tasks (Bandura, 1986). Conversely, at the start of learning activities, students persist in large part because teachers keep them working. In conditions of external influence, efficacy is a poor predictor of persistence. In clinical settings, persistence increases as self-efficacy develops, but in academic settings skill learning is involved and research has yielded inconsistent findings (Schunk, 1989a). As skills develop, higher self-efficacy may not always lead to greater persistence. Self-efficacy might relate negatively, rather than positively, to persistence, because higher skills should mean that students do not have to persist as long to answer questions or solve problems. We need additional research on the relation between efficacy and persistence in academic settings.

Research to identify appropriate indexes of academic motivation is warranted. Cognitive effort is one possibility (Corn \& Mandinach, 1983). Students spend much time during instruction attempting to understand content (Peterson, Swing, Braverman, \& Buss, 1982). It seems reasonable that students with higher efficacy for learning would engage in such productive activities as attending to instruction, rehearsing information to be remembered, organizing and making knowledge meaningful, monitoring level of understanding, and cuing memory for task-relevant knowledge. In turn, these actions should produce better learning and substantiate students' efficacy.

Research is exploring learning strategies from a motivational perspective (Borkowski, Johnston, \& Reid, 1987; Carr \& Borkowski, 1989). The findings of Pintrich and De Groot (1990) and Zimmerman and Martinez-Pons (1990) support the postulated positive relations among motivation, efficacy, and strategy use (Como, 1989; Schunk, 1989b). Future research should examine these links in greater depth, especially by investigating students' actual strategy use during learning.

\section{Transfer of Self-Efficacy and Motivation}

There is an urgent need for research on transfer of self-efficacy and motivation, that is, maintenance over time and generalization beyond the experimental context. There is evidence for transfer in clinical settings (Bandura, 1986), but in academic domains transfer typically has been confined to generalization across various content (e.g., reading passages and arithmetic problems). Transfer involves learning and motivation because it requires willingness to apply skills and strategies over extended periods, to different content, and in various settings (Borkowski, 1985).

Research should test the notion that self-efficacy contributes to transfer. Along these lines, Graham and Harris (1989b) taught learning-disabled students a strategy for writing essays. Instruction improved essay quality, gains were maintained up to 12 weeks after training, and skills and strategy use generalized to writing stories. In a similar study, learning-disabled children received strategy instruction on writing stories (Graham \& Harris, 1989a). Training improved use of story grammar elements, gains were maintained after 2 weeks, and outcomes generalized to the resource room. In both studies, strategy instruction raised self-efficacy.

The roles of self-efficacy and transfer of strategy use and achievement outcomes during writing instruction were recently investigated (Schunk \& Swartz, 1991). Children were taught a paragraph-writing strategy and received 
a goal of learning the strategy, of writing paragraphs, or of working productively (general goal). Half of the strategy goal subjects periodically received feedback on their progress in learning the strategy. Combining the strategy goal with progress feedback had the greatest benefits on self-efficacy and achievement. Gains in selfefficacy, writing skill, and strategy use maintained themselves over time and generalized across writing tasks, and self-efficacy related positively to actual strategy use.

As noted earlier, an important question concerns the generality of self-efficacy. Self-efficacy is usually defined as perceived capabilities within a specific domain (Bandura, 1986; Schunk, 1989a). Although most investigators have not investigated whether self-efficacy generalizes beyond a specific domain, there is some empirical evidence (Smith, 1989) for a generalized sense of efficacy.

In the area of cognitive skill learning, we might expect some transfer of self-efficacy from one domain to another. In new learning situations, students' aptitudes and prior experiences help form their initial judgments of efficacy for learning (Schunk, 1989b). Students with high mathematical ability who generally have performed well in mathematics would be expected to enter a new mathematical learning context with higher learning efficacy than students with lower mathematical ability who have encountered previous learning difficulties. Efficacy might transfer to the extent that the new domain builds on prior skills (e.g., efficacy for subtracting and multiplying might transfer to the learning of division). There even could be transfer to a dissimilar domain to the extent that students believe the two domains share skills. For example, students who believe that writing term papers and preparing science fair projects involve planning and organization and who feel efficacious about planning and organizing term papers may begin their first science fair project with a sense o f efficacy for succeeding. Research is needed on the issue of self-efficacy generality.

\section{Classroom Goals}

Recent work in achievement motivation has identified individual differences in conceptions of ability, beliefs about the nature of ability and the role it plays in achievement (Dweck, 1986; Dweck \& Leggett, 1988; Nicholls, 1983). An entity (fixed) view conceives of ability as a global and stable trait. Learning is possible to the limit set by ability. Students attempt to gain positive judgments of their competence from others and avoid negative judgments. Those with self-doubts work lackadaisically and expend little effort on difficult tasks. Those who believe they are capable select tasks at which they can succeed, persist longer, and expend effort. In contrast, an incremental perspective views ability as comprising skills and increasing with experience. Ability is roughly synonymous with learning. Regardless of whether students view their ability as high or low, they adopt a goal of increasing their competence, and they persist and expend effort because they believe effort enhances ability.

Wood and Bandura (1989) found that ability conceptions influence goal setting, self-efficacy, and selfregulatory activities. Subjects who had an incremental view of ability maintained high self-efficacy, set challenging goals, applied rules efficiently, and produced higher performances: Subjects who had an entity view of ability showed a decline in self-efficacy. Elliott and Dweck (1988) demonstrated that children who had learning goals chose challenging tasks and displayed effort and persistence regardless of ability assessment. Children who were given performance goals and perceived this ability as high selected challenging performance tasks that allowed them to appear competent; those who perceived ability as low selected easier tasks to avoid judgments of incompetence.

Research is needed exploring the relations among self-efficacy, goals, and motivation. Along these lines, Meece, Blumenfeld, and Hoyle (1988) assessed goals, perceived competence, motivation, and cognitive engagement. Goals were task mastery (understand material), ego/social (please others), and work avoidance (minimize effort). Active cognitive engagement referred to cognitive self-regulatory activities (student reviewed material not understood, tried to make material meaningful); superficial cognitive engagement referred to strategies to complete work with minimal effort (student copied answers, skipped hard material). Students with task-mastery goals reported more active cognitive engagement; those with high motivation to learn placed 
greater emphasis on learning goals. Perceived competence related positively to motivation and task-mastery goals.

Researchers might investigate whether self-efficacy mediates the relation between goal orientation and motivation. For example, as students work on a task and observe goal progress they believe they are becoming more skillful and that additional effort will increase learning. These beliefs should enhance efficacy, motivation, and achievement. Such students may adopt a task-mastery goal with an incremental view of ability, which should further benefit self-efficacy and motivation.

\section{Teaching Processes}

Self-efficacy and motivation are applicable to teachers as well as students. Ashton and Webb (1986) defined teaching efficacy as personal beliefs about capabilities to help students learn. Efficacy may influence teachers' activities, effort, and persistence. Teachers whose self-efficacy is low might avoid planning activities they believe exceed their capabilities, be unlikely to persist with students who are having difficulties, expend little effort to find materials, and not reteach content in ways students might understand better. In contrast, teachers whose self-efficacy is higher might develop challenging activities, help students succeed, and persevere with students who are having trouble learning. These motivational effects enhance student learning and substantiate teachers' efficacy by conveying that they can help students learn.

Research is needed on the role of self-efficacy in aspects of teaching relevant to motivation (e.g., planning and evaluating). Ashton and Webb (1986), for example, found that teachers who had higher self-efficacy were more likely to have a positive classroom environment (e.g., less student anxiety and teacher criticism), support students' ideas, and meet the needs of all students. High teaching efficacy was positively associated with use of praise (and negatively associated with criticism), individual attention to students, checking on students' progress in learning, and students' mathematical and language achievement.

Woolfolk and Hoy (1990) had prospective teachers judge efficacy, bureaucratic orientation (e.g., extent of rule conformity and organizational loyalty), pupil control ideology (custodial vs. humanistic), and motivational style (one that encouraged student autonomy and responsibility). Two efficacy dimensions were distinguished.

Teaching efficacy assessed whether teachers believed that students' motivation and performance derived mostly from home. Personal efficacy gauged whether teachers believed that with effort they could affect unmotivated students. The two measures were uncorrelated but each related to pupil control and bureaucratic orientation. Future research might address the process whereby these efficacy beliefs affect teacher and student motivation.

Researchers also should explore the effects of teacher-student interactions. When introducing content, teachers might convey that all students can learn or that some will have difficulty (Brophy, 1983). While presenting content, teachers might link new material to what students know or attempt little integration. These differences might affect students' self-efficacy and motivation. In turn, how students react to teachers should influence teachers' efficacy and motivation. Students who respond enthusiastically may enhance teachers' efficacy and motivate them to plan exciting lessons. When classes seem baffled or unenthusiastic, teachers may question their teaching competence and wonder whether additional effort will produce better results.

\section{Research Methods}

Self-efficacy research has proliferated since Bandura's (1977) seminal article. This situation is healthy, but it has led to a variety of definitions and measures of efficacy. Most researchers have developed efficacy measures appropriate for the domain they are studying. At a minimum, researchers should report reliability data in research reports. Studies also can determine the predictive validity of self-efficacy by relating efficacy measures to motivation and other outcomes such as attitudes and achievement. It is useful to include self-efficacy instruments as appendixes to articles (cf. Pintrich \& De Groot, 1990).

Kirsch (1980; Kirsch \& Wickless, 1983) argued that a problem with reliability and predictive validity of selfefficacy measures is that they constitute Guttman scales. In a Guttman scale, (a) items are ordered in difficulty, 
(b) each item can be scored as a pass or fail, and (c) the first failure in a series implies that the respondent passed all preceding items and failed all subsequent ones. The number of items that the respondent passes determines the pattern of responses: If a respondent passes 10 items on a 20 -item test, then the respondent passed the first 10 items. Reliability and other predictive uses of measures based on Guttman scales are problematic because they tend to produce artificially high coefficients.

In academic domains, the evidence does not support the assertion that efficacy tests constitute Guttman scales. Regarding the first criterion, items often can be ordered in terms of objective difficulty in domains where such ordering makes sense (e.g., mathematical computations), but ordering by difficulty becomes a problem in domains where difficulty is less objective (e.g., writing achievement). With respect to the second point, many investigators treat self-efficacy scores as continuous data and do not score them as pass or fail. In some studies (Bandura \& Schunk, 1981; Schunk, 1981), a cutting point separating high and low efficacy judgments was established; however, such cutoffs represent subjective judgments by experimenters and may not correspond with students' interpretations of what constitutes success and failure on efficacy scales.

The third criterion seldom is satisfied in academic settings. This criterion assumes a perfectly ordered task hierarchy. Even when tasks are ordered according to objective difficulty, students may not perceive them in the same order. Disparities can result when students do not fully understand what skills are required to accomplish the task. For example, many children who lack subtraction with regrouping skills judge efficacy higher for solving problems such as 9,003 - 6,571 than for solving problems such as 968,243 - 657,121. They believe that one simply subtracts the smaller number from the larger number column by column, so the first problem appears easier because it has zeros and fewer columns. In fact, the former is conceptually and computationally more difficult.

Self-efficacy researchers typically have employed quantitative methods using between-conditions comparisons in short-term studies. There is a need for data collected in other ways: longitudinal studies, case studies, and oral histories. Although such studies might include fewer subjects, they would yield rich data sources for examining the role self-efficacy plays in academic motivation. Self-efficacy assessments might be similarly broadened from reliance on numerical scales to include qualitative indexes: Subjects could describe how confident they feel about performing tasks in different situations.

In much self-efficacy research, self-reports of such measures as intentions to engage in activities and use of strategies have been used. Many studies have been conducted outside of regular classrooms. These research paradigms have advantages, but they fail to account for many aspects of classroom teaching and learning. There is an urgent need for self-efficacy research conducted in classrooms using teachers and academic content as students are learning rather than simply performing tasks. This type of research can help to extend the generality of self-efficacy theory by testing its predictions as they pertain to classroom motivation.

Attention to the research areas just described will help to clarify our understanding of the role that self-efficacy plays in academic motivation. These studies also will have implications for classroom practice. Teachers are understandably concerned about teaching students skills; however, simply possessing skills does not ensure that students will be motivated to apply them. In their instructional planning, teachers need to take into account how given procedures affect students' sense of efficacy. For example, teachers who provide students with much assistance during instruction may help students learn skills, but if students attribute the successes to the teacher they may doubt their capability to learn on their own. In this article, I have suggested several components that can be incorporated into instructional presentations to raise students' efficacy and motivation.

\section{REFERENCES}

Ashton, P. T., \& 'Webb, R. B. (1986). Making a difference: Teachers' sense of efficacy and student achievement. New York: Longman.

Atkinson, J. W. (1957). Motivational determinants of risk-taking behavior. Psychological Review, 64, 359-372. 
Bandura, A. (1977). Self-efficacy: Toward a unifying theory of behavioral change. Psychological Review, 84, 191-215.

Bandura, A. (1986). Social foundations of thought and action: A social cognitive theory. Englewood Cliffs, NJ: Prentice-Hall.

Bandura, A. (1988). Self-regulation of motivation and action through goal systems. In V. Hamilton, G. H.. Bower, \& N. H. Frijda (Eds.), Cognitive perspectives on emotion and motivation (pp. 37-61). Dordrecht, the Netherlands: Kluwer.

Bandura, A. (1989a). Human agency in social cognitive theory. American Psychologist, 44, 1175-1184.

Bandura, A. (1989b). Social cognitive theory. In R. Vasta (Ed.), Annals of child development (Vol. 6, pp. 1-60). Greenwich, CT: JAI.

Bandura, A., \& Cervone, D. (1983). Self-evaluative and self-efficacy mechanisms governing the motivational effects of goal systems. Journal of Personality and Social Psychology, 45, 1017-1028.

Bandura, A., \& Schunk, D. H. (1981). Cultivating competence, self-efficacy, and intrinsic interest through proximal self-motivation. Journal of Personality and Social Psychology, 41, 586-598.

Borkowski, J. G. (1985). Signs of intelligence: Strategy generalization and metacognition. In S. Yussen (Ed.), The growth of reflection in children (pp. 105-144). New York: Academic.

Borkowski, J. G., Johnston, M. B., \& Reid, M. K. (1987). Metacognition, motivation, and controlled performance. In S. J. Ceci (Ed.), Handbook of cognitive, social, and neuropsychological aspects of learning disabilities (Vol. 2, pp. 147-173). Hillsdale, NJ: Lawrence Erlbaum Associates, Inc.

Brophy, J. (1983). Conceptualizing student motivation. Educational Psychologist, 18, 200-215.

Brown, I., Jr., \& Inouye, D. K. (1978). Learned helplessness through modeling: The role of perceived similarity in competence. Journal of Personality and Social Psychology, 36, 900-908.

Carr, M., \& Borkowski, J. G. (1989). Attributional training and the generalization of reading strategies with underachieving children. Learning and Individual Differences, 1, 327-341.

Collins, J. (1982, March). Self-efficacy and ability in achievement behavior. Paper presented at the meeting of the American Educational Research Association, New York.

Corno, L. (1989). Self-regulated learning: A volitional analysis. In B. J. Zimmerman \& D. H. Schunk (Eds.), Self-regulated learning and academic achievement: Theory, research, and practice (pp. 111-141). New York: Springer-Verlag.

Corno, L., \& Mandinach, E. B. (1983). The role of cognitive engagement in classroom learning and motivation. Educational Psychologist, 18, 88-108.

Dweck, C. S. (1986). Motivational processes affecting learning. American Psychologist, 41, 1040-1048.

Dweck, C. S., \& Leggett, E. L. (1988). A social-cognitive approach to motivation and personality.

Psychological Review, 95, 256-273.

Eccles, J. (1983). Expectancies, values, and academic behaviors. In J. T. Spence (Ed.), Achievement and achievement motives: Psychological and sociological approaches (pp. 75-146). San Francisco: Freeman. Elliott, E. S., \& Dweck, C. S. (1988). Goals: An approach to motivation and achievement. Journal of Personality and Social Psychology, 54, 5-12.

Foersterling, F. (1985). Attributional retraining: A review. Psychological Bulletin, 98, 495-512.

Graham, S., \& Harris, K. R. (1989a). Components analysis of cognitive strategy instruction: Effects on learning disabled students' compositions and self-efficacy. Journal of Educational Psychology, 81, 353-361.

Graham, S., \& Harris, K. R. (1989b). Improving learning disabled students' skills at

composing essays: Self-instructional strategy training. Exceptional Children, 56, 210-214. Heider, F. (1958).

The psychology of interpersonal relations. New York: Wiley.

Kelley, H. H., \& Michela, J. (1980). Attribution theory and research. Annual Review of Psychology, 31, 457501.

Kirsch, I. (1980). "Microanalytic" analyses of efficacy expectations as predictors of performance. Cognitive Therapy and Research, 4, 259-262.

Kirsch, I., \& Wickless, C. V. (1983). Concordance rates between self-efficacy and approach behavior are redundant. Cognitive Therapy and Research, 7,179-188. 
Lepper, M. R. (1983). Extrinsic reward and intrinsic motivation: Implications for the classroom. In J. M. Levine \& M. C. Wang (Eds.), Teacher and student perceptions:

Implications for learning (pp. 281-317). Hillsdale, NJ: Lawrence Erlbaum Associates, Inc.

Locke, E. A., Frederick, E., Lee, C., \& Bobko, P. (1984). Effect of self-efficacy, goals, and task strategies on task performance. Journal of Applied Psychology, 69, 241-251.

Locke, E. A., \& Latham, G. P. (1990). A theory of goal setting and task performance. Englewood Cliffs, NJ: Prentice-Hall.

Marsh, H. W., \& Shavelson, R. (1985). Self-concept: Its multifaceted, hierarchical structure. Educational Psychologist, 20, 107-123.

Meece, J. L., Blumenfeld, P. C., \& Hoyle, R. H. (1988). Students' goal orientations and cognitive engagement in classroom activities. Journal of Educational Psychology, 80, 514-523.

Meier, S., McCarthy, P. R., \& Schmeck, R. R. (1984). Validity of self-efficacy as a predictor of writing performance. Cognitive Therapy and Research, 8, 107-120.

Morgan, M. (1985). Self-monitoring of attained subgoals in private study. Journal of Educational Psychology, 77,623-630.

Nicholls, J. C. (1983). Conceptions of ability and achievement motivation: A theory and its implications for education. In S. G. Paris, G. M. Olson, \& H. W. Stevenson (Eds.), Learning and motivation in the classroom (pp. 211-237). Hillsdale, NJ: Lawrence Erlbaum Associates, Inc.

Peterson, P. L., Swing, S. R., Braverman, M. T., \& Buss, R. (1982). Students' aptitudes and their reports of cognitive processes during direct instruction. Journal of Educational Psychology, 74, 535-547.

Pintrich, P. R., \& De Groot, E. V. (1990). Motivational and self-regulated learning components of classroom academic performance. Journal of Educational Psychology, 82, 33-40.

Relich, J. D., Debus, R. L., \& Walker, R. (1986). The mediating role of attribution and self-efficacy variables for treatment effects on achievement outcomes. Contemporary Educational Psychology, 11, 195-216.

Romberg, T. A., \& Carpenter, T. P. (1986). Research on teaching and learning mathematics: Two disciplines of scientific inquiry. In M. C. Wittrock (Ed.), Handbook of research on teaching (3rd ed., pp. 850-873). New York: Macmillan.

Rosenberg, M., \& Kaplan, H. B. (1982). Social psychology of the self-concept. Arlington Heights, IL: Harlan Davidson.

Rotter, J. B. (1966). Generalized expectancies for internal versus external control of reinforcement. Psychological Monographs, 80 (Whole No. 609).

Salomon, G. (1984). Television is "easy" and print is "tough": The differential investment of mental effort in learning as a function of perceptions and attributions. Journal of Educational Psychology, 76,647-658.

Scardamalia, M., \& Bereiter, C. (1986). Research on written composition. In M. C. Wittrock

(Ed.), Handbook of research on teaching (3rd ed., pp. 778-803). New York: Macmillan. Schunk, D. H. (1981). Modeling and attributional effects on children's achievement: A self-efficacy analysis. Journal of Educational Psychology, 73, 93-105.

Schunk, D. H. (1982). Effects of effort attributional feedback on children's perceived self-efficacy and achievement. Journal of Educational Psychology, 74, 548-556.

Schunk, D. H. (1983a). Ability versus effort attributional feedback: Differential effects on self-efficacy and achievement. Journal of Educational Psychology, 75, 848-856.

Schunk, D. H. (1983b). Developing children's self-efficacy and skills: The roles of social comparative information and goal setting. Contemporary Educational Psychology, 8, 76-86.

Schunk, D. H. (1983c). Goal difficulty and attainment information: Effects on children's achievement behaviors. Human Learning, 2, 107-117.

Schunk, D. H. (1983d). Reward contingencies and the development of children's skills and self-efficacy. Journal of Educational Psychology, 75, 511-518.

Schunk, D. H. (1984). Enhancing self-efficacy and achievement through rewards and goals: Motivational and informational effects. Journal of Educational Research, 78, 29-34.

Schunk, D. H. (1985). Participation in goal setting: Effects on self-efficacy and skills of learning disabled children. Journal of Special Education, 19, 307-317. 
Schunk, D. H. (1987). Peer models and children's behavioral change. Review of Educational Research, 57,149174.

Schunk, D. H. (1989a). Self-efficacy and achievement behaviors. Educational Psychology Review, 1, 173-208. Schunk, D. H. (1989b). Self-efficacy and cognitive skill learning. In C. Ames \& R. Ames (Eds.), Research on motivation in education: Vol. 3. Goals and cognitions (pp. 13-44). San Diego: Academic.

Schunk, D. H., \& Cox, P. D. (1986). Strategy training and attributional feedback with learning disabled students. Journal of Educational Psychology, 78, 201-209.

Schunk, D. H. \& Gunn, T. P. (1985). Modeled importance of task strategies and achievement beliefs: Effects on self-efficacy and skill development. Journal of Early Adolescence, 5, 247-258.

Schunk, D. H., \& Hanson, A. R. (1985). Peer models: Influence on children's self-efficacy and achievement. Journal of Educational Psychology, 77,313-322.

Schunk, D. H., \& Hanson, A. R. (1989). Self-modeling and children's cognitive skill learning. Journal of Educational Psychology, 81, 155-163.

Schunk, D. H., Hanson, A. R., \& Cox, P. D. (1987). Peer-model attributes and children's achievement behaviors. Journal of Educational Psychology, 79, 54-61.

Schunk, D. H., \& Swartz, C. W. (1991). Goals and progress feedback: Effects on self-efficacy and writing achievement. Unpublished manuscript, University of North Carolina, Chapel Hill.

Seligman, M. E. P. (1975). Helplessness: On depression, development, and death. San Francisco: Freeman.

Shavelson, R. J., \& Bolus, R. (1982). Self-concept: The interplay of theory and methods. Journal of

Educational Psychology, 74, 3-17.

Shell, D. F., Murphy, C. C., \& Bruning, R. H. (1989). Self-efficacy and outcome expectancy mechanisms in reading and writing achievement. Journal of Educational Psychology, 81, 91-100.

Skinner, E. A., Chapman, M., \& Baltes, P. B. (1988). Control, means-ends, and agency beliefs: A new conceptualization and its measurement during childhood. Journal of Personality and Social Psychology, 54, 117-133.

Skinner, E. A., Wellborn, J. G., \& Connell, J. P. (1990). What it takes to do well in school and whether I've got it: A process model of perceived control and children's engagement and achievement in school. Journal of Educational Psychology, 82, 22-32.

Smith, R. E. (1989). Effects of coping skills training on generalized self-efficacy and locus of control. Journal of Personality and Social Psychology, 56, 228-233.

Tolman, E. C. (1932). Purposive behavior in animals and men. New York: AppletonCentury-Crofts.

Vroom, V. H. (1964). Work and motivation. New York: Wiley.

Weiner, B. (1979). A theory of motivation for some classroom experiences. Journal of Educational Psychology, 71, 3-25.

Weiner, B. (1985). Human motivation. New York: Springer-Verlag.

Weinstein, C. E., \& Mayer, R. E. (1986). The teaching of learning strategies. In M. C. Wittrock (Ed.), Handbook of research on teaching (3rd ed., pp. 315-327). New York: Macmillan.

Wood, R., \& Bandura, A. (1989). Impact of conceptions of ability on self-regulatory mechanisms and complex decision-making. Journal of Personality and Social Psychology, 56, 407-415.

Woolfolk, A. E., \& Hoy, W. K. (1990). Prospective teachers' sense of efficacy and beliefs about control. Journal of Educational Psychology, 82, 81-91.

Zimmerman, B. .1., \& Martinez-Pons, M. (1990). Student differences in self-regulated learning: Relating grade, sex, and giftedness to self-efficacy and strategy use. Journal of Educational Psychology, 82, 51-59.

Zimmerman, B. J., \& Ringle, J. (1981). Effects of model persistence and statements of confidence on children's self-efficacy and problem solving. Journal of Educational Psychology, 73, 485-493. 